\title{
The Influence of Ascorbic Acid on in Vitro Maturation of Canine Oocytes
}

\author{
Anamaria PERNES*, Ileana MICLEA, Marius ZAHAN, Vasile MICLEA, Delia ORLOVSCHI, Andrei Răzvan \\ CODEA
}

University of Agricultural Sciences and Veterinary Medicine, Faculty of Animal Science and Biotechnologies, 3-5 Mănăștur Street, 400372 Cluj-Napoca, România

* corresponding author: pernes.jeni@gmail.com

Bulletin UASVM Animal Science and Biotechnologies 73(2)/ 2016

Print ISSN 1843-5262; Electronic ISSN 1843-536X

DOI:10.15835/buasvmcn-asb: 12320

\begin{abstract}
It is known that L-ascorbic acid (vitamin C) can modulate many biochemical processes intracellularly or extracellularly as antioxidant. The aim of the present study was to examine the effects of media supplementation with ascorbic acid on canine oocyte meiotic maturation, viability and the cumulus cell expansion. Various concentrations of ascorbic acid supplemented in in vitro maturation (IVM) media were tested. Canine oocyte was exposed to different levels of ascorbic acid $(0,50,150,250,500,750 \mu \mathrm{M})$. Cumulus expansion, meiotic maturation and degeneration of oocytes were assessed $72 \mathrm{~h}$ after in vitro culture. As results, on the group treated with $250 \mu \mathrm{M}$ ascorbic acid was a significant difference compared to the control group on nuclear maturation in stages metaphase I (MI) and metaphase II (MII) (26.98\% vs. 6.00\%). The groups treated with 50, 150, 250, 500 $\mu \mathrm{M}$ had an increase in stage (GVBD), and a significant decrease of degenerate-undefined oocytes compared with the control $(23.31 \%$, $18.85 \%, 13.41 \%$ vs 40.80 ). Concentration $750 \mu \mathrm{M}$ had similar effect to that in the control group. The groups treated with 50,150, 250,500 $\mathrm{M}$ had an increase in meiosis resumption (GVBD), metaphase I (MI) and metaphase II (MII) with the best result in the group treated with $250 \mu \mathrm{M}$ ascorbic acid.
\end{abstract}

Keywords: ascorbic acid, canine, in vitro maturation, oocytes

\section{INTRODUCTION}

The development of in vitro techniques using the canine oocyte as an experimental model would retain powerful tools for gamete rescue programs, which are important to preserve the existence of various endangered canid species (Hewitt and England, 2001; Otoi et al., 2002), as a model for studying human genetic disorders. Domestic dogs exhibit spontaneous occurrence of cancers, and as pets, they are exposed to environmental factors common to humans (Davis and Ostrander, 2014; Switonski, 2014). The 350 traits/disorders identified in the dog with potential to be models for human disease is almost twice that of any other species (Nicholas, 2003).

Development of assisted reproductive technologies (ART) in the dog has resisted progress for decades, due to their unique reproductive physiology. The oocyte of the domestic dog is unique from that of other mammalian species studied to date. Ovulation occurs either once or twice per year, with the oocyte released at the germinal vesicle stage and then completing nuclear and cytoplasmic maturation within the oviduct, and requires $48-72 \mathrm{~h}$ in the oviduct post-ovulation to complete nuclear maturation (Reynaud et al., 2005). From 1976 (Mahi and Yanagimaci, 1976) to date, numerous studies have been conducted to improve success of in vitro maturation (IVM) of bitch oocytes but an efficient protocol for IVM has not been established. In vitro maturation, generally has resulted in low rates of successful resumption of meiosis, with the exception being one study that found that use of oocytes from follicles larger than $2 \mathrm{~mm}$ yielded significantly higher rates of metaphase 
II development in vitro (Songsasen and Wildt, 2005), where $79.5 \%$ of oocytes recovered from follicles $2 \mathrm{~mm}$ size reached the second metaphase (MII), usually less than $20 \%$ of canine oocytes achieve nuclear maturation (Songsasen and Wildt, 2007). Moreover, only a single blastocyst has been produced after in vitro fertilization of in vitro matured oocytes (Otoi et al., 2000).

Age of the donor bitch (Hewitt and England, 1998; Songsasen et al., 2002), stage of the reproductive cycle (Yamada et al., 1993; Otoi et al., 2001), oocyte diameter (Otoi et al., 2000; Ariu et al., 2011), and the size of the ovarian follicle (Songsasen and Wildt, 2005) are factors influencing meiotic competence of bitch oocytes cultured in vitro. In particular, oocyte diameter may be a useful selection parameter. It has been reported (Otoi et al., 2000) that large oocytes $(>120 \mu \mathrm{m}$ diameter) had a higher frequency of maturation than oocytes $(<110 \mu \mathrm{m}$ diameter $)$. This result also suggests the importance of selecting good quality of cumulus-oocyte complexes (COCs) by morphological appearance for IVM of oocytes. Low maturation rates could be due to either suboptimal culture conditions or low meiotic competence of the oocytes (Farstad, 2000). Vitamins are indispensable nutrients involved in a variety of multiple cell functions and they are also essential for mammalian reproduction (Meister and Tate, 1976; Hurley and Doane, 1989). They function not only as cellular antioxidants, but also as modulators of many intracellular or extracellular biochemical processes. Ascorbic acid (vitamin $\mathrm{C}$ ) is functional in many biological processes such as the biosynthesis of collagen and other components of the extracellular matrix and is the most important antioxidant in extracellular fluids (Buettner, 1993). Predominant in preovulatory follicles in rat ovaries (Guarnaccia et al., 2000), ascorbic acid prevents follicular apoptosis in cultured rat (Tilly and Tilly, 1995) and mouse follicles (Eppig et al., 2000). Ascorbic acid enhances porcine oocyte developmental competence (Tatemoto et al., 2001) and prevents the apoptosis of granulosa cells (Murray et al., 2001) and ovarian follicular cells (Tilly and Tilly, 1995). Few systematic studies have investigated the function of ascorbic acid on oocyte in vitro maturation. The aim of the present study was to examine the effects of media supplementation with various concentrations $(0,50,150,250,500$,
$750 \mu \mathrm{M}$ ) of ascorbic acid on canine oocyte meiotic maturation in vitro.

\section{MATERIALS AND METHODS}

All the chemicals used in this study were purchased from Sigma-Aldrich (USA). To investigate the effect of ascorbic acid for improving oocyte maturation, in vitro maturation (IVM) TCM-199 medium was supplemented with five concentrations $50,150,250,500,750 \mu \mathrm{M}$ acid ascorbic during $72 \mathrm{~h}$ in vitro culture.

Reproductive tracts from normal bitches greater than 6 months of age of different breeds and at various stages of their estrus cycle, were collected after routine ovariohysterectomy at private clinics, placed immediately into physiological saline solution at $37^{\circ} \mathrm{C}$ supplemented with penicillin $\mathrm{G}$ and streptomycin sulfate, and transported back to the laboratory within $1 \mathrm{~h}$. Ovaries were removed from the tract and washed free from blood in fresh physiological saline solution.

Cumulus-oocyte complexes (COCs) were released by slicing the ovarian cortex with a scalpel blade; oocytes were washed in the bench medium to wash of blood and other debris prior to transfer to maturation medium. Cumulus-oocyte complexes (COCs) which has compact and more than three layers of cumulus cells, dark oocyte cytoplasm were selected (Hewitt and England, 1998) and transferred in IVM medium containing TCM-199 supplemented with sodium pyruvate, fetal bovine serum (FBS) $10 \%$, Folligon $(10 \mathrm{IU} / \mathrm{ml})$, Chorulon (10 IU/ml), $\beta$-estradiol and antibiotics (penicillin, streptomycin, gentamicin) under paraffin oil for $72 \mathrm{~h}$ at $37^{\circ} \mathrm{C}$ (Luvoni et al., 2001) in an atmosphere of $5 \% \mathrm{CO}_{2}$ and $95 \%$ air humidity. To investigate the effect various concentrations of ascorbic acid were tested 0.0 (control), 50, 150, 250,500 and $750 \mu \mathrm{M}$.

At the end of the maturation culture, oocytes were completely denuded by gently pipetting with phosphate buffer saline (PBS) and $0.1 \%$ PVA. After $72 \mathrm{~h}$ of in vitro culture, oocytes were evaluated for viability and nuclear meiotic stage under fluorescence microscopy (Olympus IX 51) with UV light. The effect of ascorbic acid on the percentages of oocytes reaching various stages of nuclear maturation compared to the control and the differences analyzed using the analysis of variance and interpreted using the Tukey test 
and the IBM SPSS software. Differences of $\mathrm{P}<0.05$ were considered significant.

\section{RESULTS AND DISCUSSION}

COCs were obtained by slicing the ovarian cortex from bitches at various stages of their estrus cycle. The progression of meiosis was evaluated after staining with propidium iodide under fluorescence microscopy and the data are summarized in (Table 1). Results demonstrated that incubation with $50,150,250$ or $500 \mu \mathrm{M}$ ascorbic acid showed a decrease in the proportion of oocytes that remained at the germinal vesicle stage (GV) compared to the control group. The percentage of GVBD oocytes in the $750 \mu \mathrm{M}$ (15.21\%) group was similar to that in the control group (18.78\%), but a significantly higher proportion was in the $250 \mu \mathrm{M}$ group $(\mathrm{P}<0.05)$

The percentage of oocytes reaching MI/MII stage was significantly higher after incubation with 150 or $250 \mu \mathrm{M}$ ascorbic acid $(\mathrm{P}<0.001$, $23.61 \%$ or $26.98 \%$ ) compared with the control group $(6.00 \%)$ and the incubation with $250 \mu \mathrm{M}$ was significantly higher $(\mathrm{p}<0.05)$ compared with the other groups. The groups treated with 50, 150, $250 \mu \mathrm{M}$ had a significantly decrease of degenerateundefined oocytes compared with the control $(23.31 \%, 18.85 \%, 13.41 \%$ vs 40.80$)$ and the group treated with the $750 \mu \mathrm{M}$ had similar effect to that in the control group.

Dog oocytes, like those of other species, are able to resume meiosis in vitro, but are not fully competent to complete nuclear maturation. From 1976 (Mahi and Yanagimaci, 1976) to date, numerous studies have been conducted to improve success of in vitro maturation (IVM) of

Tab. 1. Meiotic status of canine oocytes cultured in TCM-199 supplemented with ascorbic acid

\begin{tabular}{cccccc}
\hline Concentrations $(\mu \mathrm{M})$ & $\begin{array}{c}\text { Number of } \\
\text { oocytes }\end{array}$ & & \multicolumn{3}{l}{ \%nuclear status of oocytes (mean \pm SD) } \\
\hline & & GV & GVBD & MI/MII & DEG/UND \\
\hline 0 & 53 & $34.40 \pm 9.99$ & $18.79 \pm 10.34^{\mathrm{a}}$ & $6.01 \pm 5.97^{\mathrm{a}}$ & $40.81 \pm 9.06^{\mathrm{a}}$ \\
\hline 50 & 54 & $27.65 \pm 6.08$ & $32.89 \pm 9.92$ & $16.15 \pm 8.86$ & $23.31 \pm 8.39^{\mathrm{b}}$ \\
\hline 150 & 55 & $27.57 \pm 6.05$ & $29.96 \pm 10.17$ & $23.61 \pm 1.96^{\mathrm{b}}$ & $18.85 \pm 8.82^{\mathrm{b}}$ \\
\hline 250 & 57 & $24.01 \pm 3.46$ & $35.59 \pm 8.35^{\mathrm{b}}$ & $26.99 \pm 6.79^{\mathrm{b}}$ & $13.42 \pm 8.15^{\mathrm{b}}$ \\
\hline 500 & 55 & $28.31 \pm 9.16$ & $31.16 \pm 10.28$ & $13.92 \pm 6.90$ & $26.61 \pm 13.24$ \\
\hline 750 & 52 & $35.17 \pm 9.33$ & $15.22 \pm 11.01$ & $8.87 \pm 7.26$ & $40.75 \pm 13.26$ \\
\hline GV, germinal vesicle; GVBD, germinal vesicle break down; MI/MII metaphase 1/II; DEG/UND, degenerate/undefined oocytes. Different
\end{tabular}

bitch oocytes but an efficient protocol for IVM has not been established.

The influence of various factors on the in vitro maturation of canine oocytes such as age of the donor bitch (Hewitt and England, 1998; Songsasen et al., 2002) the stage of the reproductive cycle (Yamada et al., 1993; Otoi et al., 2001), oocyte diameter (Ariu et al., 2011; Otoi et al., 2000), the size of the ovarian follicle (Songsasen and Wildt, 2005) using hormonal supplementation (Apparicio et al., 2011) have been tested to improve canine IVM system. Nevertheless, efforts to assess various factors have provided a lot of valuable information for the advancement of canine IVM system. Some investigators have indicated no association on the relationship between stage of reproductive cycle and oocyte meiotic competence (Hossein et al., 2007; Otoi et al., 2002; Songsasen and Wildt, 2005) whereas others have demonstrated that reproductive cycle stage significantly impacts developmental capacity of the oocyte (Yamada et al., 1993; Otoi et al., 2001; Luvoni et al., 2001; Kim et al., 2004). In the present study, higher proportion of oocytes reached MI and MII stage in the presence of ascorbic acid at certain concentrations compared to those in the control group. It has been shown that ascorbic acid protects cells from oxidative stress and improve maturation on mouse oocytes (Eppig et al., 2000).

Predominant in preovulatory follicles in rat ovaries (Guarnaccia et al., 2000) ascorbic acid prevents follicular apoptosis in cultured rat (Tilly and Tilly, 1995) enhanced porcine oocyte developmental competence (Tatemoto et al., 2001; Miclea et al., 2012), improved the suboptimal culture conditions for porcine parthenotes and 
cloned embryos (Kere et al.,2013) and prevents the apoptosis of granulosa cells (Murray et al., 2001) and ovarian follicular cells (Tilly and Tilly, 1995). The results of this study showed that ascorbic acid increases meiotic resumption of canine oocytes. The highest percentage of maturation to MI/MII stage was in the groups treated with 150 or $250 \mu \mathrm{M}$ ascorbic acid, but it also impose some side effects by decreasing the maturation rate at $750 \mu \mathrm{M}$. That may be because ascorbic acid has two different actions: an antioxidant action at lower concentrations, and a pro-oxidant action at higher concentrations (Tatemoto et al., 2001). Our results suggest that ascorbic acid increases meiotic resumption of canine oocytes at certain concentrations. The highest rate of maturation to metaphase I/II stage was obtained after treatment of oocytes with $250 \mu \mathrm{M}$. This is similar to work of other authors (Tao et al., 2004; Tatemoto et al., 2001; Eppig et al., 2000). In canine species recent reports also showed that addition of $\beta$-mercaptoethanol ( $\beta$-ME) (Kim et al., 2004), cysteine and cysteamine (Hossein et al., 2007), polyether fatty acid, okadaic acid (Ariu et al., 2011), 9-cis retinoic acid (Liang et al., 2012) to IVM media improved meiotic competence of oocytes.

In conclusion, the addition of ascorbic acid at certain concentration $(250 \mu \mathrm{M})$ to the in vitro maturation system of canine oocytes increases meiotic resumption and maturation rates to MI/ MII.

\section{REFERENCES}

1. Apparicio M, Alves, A, Pires-Butler, E Ribeiro A, Covizzi G, Vicente W (2011). Effects of Hormonal Supplementation on Nuclear Maturation and Cortical Granules Distribution of Canine Oocytes During Various Reproductive Stages. Reprod Domest Anim 46 (5):896-903.

2. Ariu F, Fois S, Bebbere D, Ledda S, Rosati I, Zedda M, Pau S, Bogliolo L (2011). The effect of okadaic acid on meiotic maturation of canine oocytes of different size. Theriogenology 77 (1): 46-52.

3. Buettner GR (1993). The pecking order of free radicals and antioxidants: lipid peroxidation, a-tocopherol and ascorbate. Arch Biochem Biophys 300:535-43.

4. Davis BW, Ostrander EA (2014). Domestic dogs and cancer research: A breed-based genomics approach.ILAR J. 55(1):59-68.

5. Eppig JJ, Hosoe M, O’Brien MJ, Pendola FM, Requena A, Watanabe S (2000). Conditions that affect acquisition of developmental competence by mouse oocytes in vitro: FSH, insulin, glucose and ascorbic acid. Mol Cell Endocrinol 163:109-16.
6. Farstad W (2000). Current state in biotechnology in canine and feline reproduction. Anim Reprod Sci 60-61:375-87.

7. Guarnaccia MM, Takami M, Jones EE, Preston SL, Behrman HR (2000). Luteinizing hormone depletes ascorbic acid in preovulatory follicles. Fertil Steril 74:959-63.

8. Hewitt DA, England GC (2001). Manipulation of canine fertility using in vitro culture techniques. J Reprod Fertil (57 Suppl.): 111-25.

9. Hewitt DA, England GCW (1998). The effect of oocytes maturation and age upon oocyte nuclear maturation in vitro. Theriogenology 49:957- 66.

10. Hossein M, Kim M, Jang G, Oh H, Koo O, Kim, J, Kang, S, Lee B, Hwang W (2007). Effects of thiol compounds on in vitro maturation of canine oocytes collected from different reproductive stages. Mol Reprod Dev.74(9):1213-20.

11. Hurley WL, Doane RM (1989). Recent developments in the roles of vitamins and minerals in reproduction. J. Dairy Sci. 72:784-804.

12. Kere M, Siriboon C, Lo NW, Nguyen NT (2013). Ascorbic acid improves the developmental competence of porcine oocytes after parthenogenetic activation and somatic cell nuclear transplantation. J Reprod. Dev. 59:78-84.

13. Kim MK, Fibrianto YH, Oh HJ, Jang G, Kim HJ, Lee KS et al (2004). Effect of beta-mercaptoethanol or epidermal growth factor supplementation on in vitro maturation of canine oocytes collected from dogs with different stages of the estrus cycle. J Vet Sci 5:253-8.

14. Liang S, Kang J, Jin H, Liu X, Li J, Li S, Lu Y, Wang W, Yin XJ (2012). The influence of 9-cis-retinoic acid on nuclear and cytoplasmic maturation and gene expression in canine oocytes during in vitro maturation. Theriogenology. 77(6):1198-205.

15. Luvoni GC, Luciano AM, Modina S, Gandol F (2001). Influence of different stages of the oestrous cycle on cumulus-oocyte communications in canine oocytes: effects on the efciency of in vitro maturation. J Reprod Fertil Suppl 57:141-46.

16. Mahi CA, Yanagimaci R (1976). Maturation and sperm penetration of canine oocytes in vitro. Exp Zool 16:189 $-93$.

17. Meister A, Tate SS (1976). Glutathione and related g-glutamyl compounds: biosynthesis and utilization. Annu Rev Biochem 45:559-604.

18. Miclea I, Pacala N, Zahan M, Orlovschi D, Carlea L, Miclea V (2012). Alpha-tocopherol and ascorbic acid combination have a positive effect on the maturation of pig oocytes. Bulletin UASVM Animal Science and Biotechnologies, 69:1-2.

19. Murray AA, Molinek MD, Baker SJ, Kojima FN, Smith MF, Hillier SG, Spears N (2001). Role of ascorbic acid in promoting follicle integrity and survival in intact mouse ovarian follicles in vitro. Reproduction 121:89-96.

20. Nicholas FW (2003). Online Mendelian Inheritance in Animals (OMIA): a comparative knowledge base of genetic disorders and other familial traits in non-laboratory animals. Nucleic Acids Res. 31 (1):275-7.

21. Reynaud K, Fontbonne A, Marseloo N, Thoumire S, Chebrout M, de Lesegno C.V, Chastant-Maillard S (2005). 
In vivo meiotic resumption, fertilization and early embryonic development in the bitch. Reproduction.130 (2):193-201.

22. Otoi T, Fujii M, Tanaka M, Ooka A, Suzuki T (2000). Canine oocyte diameter in relation to meiotic competence and sperm penetration. Theriogenology 54:535- 42.

23. Otoi T, Ooka A, Murakami M, Kurniani Karja NW, Suzuki $\mathrm{T}$ (2001). Size distribution and meiotic competence of oocytes obtained from bitch ovaries at various stages of the oestrous cycle. Reprod Fertil Dev. 13:151-5.

24. Otoi T, Willingham L, Shin T, Kraemer DC, Westhusin M (2002). Effects of oocyte culture density on meiotic competence of canine oocytes. Reproduction 124:775-81.

25. Songsasen N, Yu I, Leibo SP (2002). Nuclear maturation of canine oocytes cultured in protein-free media. Mol Reprod Dev 62:407-15.

26. Songsasen N, Wildt DE (2005). Size of the donor follicle, but not stage of reproductive cycle or seasonality, inuences meiotic competency of selected domestic dog oocytes. Mol Reprod Dev 72:113-9.

27. Songsasen N, Wildt DE (2007). Oocyte biology and challenges in developing in vitro maturation systems in the domestic dog. Anim Reprod Sci 98:2-22.
28. Switonski M (2014). Dog as a model in studies on human hereditary diseases and their gene therapy. Rep Biol. 14(1):44-50.

29. Tao Y, Zhou B, Xia G, Wang F, Wu Z, Fu M (2004). Exposure to L-ascorbic acid or alpha-tocopherol facilitates the development of porcine denuded oocytes from metaphase I to metaphase II and prevents cumulus cells from fragmentation. Reprod Domest Anim 39:52-57.

30. Tatemoto H, Ootaki K, Shigeta K, Muto N (2001). Enhancement of developmental competence after in vitro fertilization of porcine oocytes by treatment with ascorbic acid 2-0-a- glucoside during in vitro maturation. Biol Reprod. 65:1800-1806

31. Tilly JL, Tilly KI (1995). Inhibitors of oxidative stress mimic the ability of follicle-stimulating hormone to suppress apoptosis in cultured rat ovarian follicles. Endocrinology 136: 242-52.

32. Yamada S, Shimazu Y, Kawano Y, Nakazawa M, Naito K, Toyoda Y (1993). In vitro maturation and fertilization of preovulatory dog oocytes. Reprod Fertil 47:227-9. 